\title{
Nurse Perceptions About the Culture of Reporting Medication Error in Taif- Hospital
}

\author{
Dr .Magda A.M.Mansour, Latifah Hamoud AL-Gethami \\ Ass.prof.adult nursing -Assiut University, Taif University. \\ Applied Medical Science- Taif University.
}

\begin{abstract}
:
Introduction and research problem: Medication errors in hospitals are very common and it caused huge trouble in community, So, the present study aimed to: Identify nurse perceptions about the Culture of Reporting medication error in Taif -hospitals. Research methodology: Across -sectional descriptive survey, a total of 150 nurses, in multiple settings, both, King Faisal, 68(45.3\%), Abdul-Aziz,37(24.7\%) and Pediatric hospital,45(30\%), at Taif City.Tool of data collection Structured interview questionnaire was used and composed of two parts. The first part was related to demographic data, aged, sex, working position, level of education and the second part was a Survey to seek Information about the reporting of medication errors, which is designed by Allina Hospitals, 2002. Results: Participants age ranged between 22 and 59 years old with Mean \pm SD (30.24+_8.10)years ,the majority is diploma degree, staff nurse and female, $(74.3 \%, 85.3 \%$ and $73.3 \%$,respectively ),their experience ranged between 1 36 with means and SD , ( $\left.6.76 \&+\_7.03\right)$ years. Also majority of participants strongly agree regarding use of new technology, good leadership and blame-free reporting, have a vital role in preventing medication error. Conclusion: Reporting errors in a clear and transparent with no blame in workplace, decreasing workloads, applying quality standards, informatics technology and selecting qualified health personnel are the suitable solution for reducing medication errors. Recommendations: Preparing an educational training course for documenting and reporting system through utilization of information technology and quality standards in medication administration according to hospital police .
\end{abstract}

Keywords: Medication error ;culture, Nurse ,Report.

\section{Introduction:}

Organization have cultures, and daily work life is infused with it. Culture influences communication, social relations and individual actions and motivation, as well as the rules.perspective, and ideals by which people live factors such as how nursing units are arranged, the working atmosphere, and the relation among people vary among organization, even within the same industry. (Hecht, Jackson and pitts,2005).

Errors are more likely to be reported when clinicians, feel safe to do so $\&$ becomes a culturally accepted activity. Failure or resistance to reporting errors because of fear is characteristic of a cultured of blame. A culture of blame is exemplified by lack the lack of communication \& silence following medical errors \& adverse events.(Cochen,2000and Larson,2000).

Medication errors occur frequently and have significant clinical and financial consequences. Several types of information technologies can be used to decrease rates of medication errors. Computerized physician order entry with decision support significantly reduces serious inpatient medication error rates in adults. Other available information technologies that may prove effective for inpatients include computerized medication administration records, robots, automated pharmacy systems, bar coding, "smart" intravenous devices, and computerized discharge prescriptions and instructions. (kaushal,and Bates,2002)

Drug treatment in the hospital setting requires a series of actions to be performed correctly by several members of the healthcare team, such as the physician, the unit clerk, the hospital pharmacist and the nurse. (Arun,et al --,2006).

Ansari and Neupane ,(2009).reported that, The error on writing name and signature of prescriber, $85.4 \%$ and $15.7 \%$ respectively . the errors in writing dose $(18.9 \%)$, duration $(59.9 \%)$, dosage form $(12.1 \%)$, route $(62.6 \%)$ and illegible writing $(0.63 \%)$.

Other study in gulf, by Irshaid et al-(2005), in Saudi Arabia , $16.7 \%$ and 18.1 percent respectively. It is common to prescribe medicines without writing name and signature of prescriber.

In professional practice, the central tenant of cultural safety is that rather that the nurse determining what is culturally safe, it is the recipient of that care who decides whether they feel safe with the care that is given (Hughes \& Farrow, 2006).

Nurses are in a unique position to improve patient safety because of their inherent proximity to patients. This position gives nurses the needed insight to identify problems in healthcare systems and to be

Vol , (1) No , (1) June 2013 
part of patient safety solutions. However, to do this, nurses must be supported and encouraged without fear of retribution, as well as have an understanding of how organizational culture change can be accomplished (Mary, et al.., 2005 ).

Nurses can act to prevent the dispensing of drugs against poorly written prescriptions by doctors. Nurses empowered to report Adverse drug

events(ADEs) were shown to be as effective as doctors ,and this has led to extension of their powers to write yellow cards reporting ADEs. As dispensers of drugs to patients in hospitals, nurses themselves may be a source of medication errors ,e.g by issuing the wrong drug to a particular patient or making errors in dosage or timing. Factors increasing the risk of medication errors by nurses include multiple distractions and interruptions and a lack of focus during tasks (Qureshi, et.al--,2011\& Penny et al...,2008 )

\section{The present study aimed to :}

Identify nurse perceptions about the Culture of Reporting medication error in Taif-hospitals

\section{Research Methodology}

Research Design:

A cross- sectional-descriptive survey was carried out for the present study.

\section{Setting}

The study was conducted in critical care units namely Intensive care unit(ICU), Coronary care unit(CCU) and Emergency unit( ER ) .this units are affiliated to three hospitals in Taif - City namely , King Faisal (3units), Abdul-Aziz(3units), and Pediatric hospital(3units) .

Subjects

A total number of Nurses 150 who are working in the previously mentioned setting and available at the time of data collection were included in this study.partipations number \& percent 68 (45.3\%), 37 (24.7\%) and45 (30\%),respectively) .

Participant nurses age ranged between 22 and 59 years old with Mean \pm SD (30.24+_8.10)years \& $74.3 \%$ diploma , $46.6 \%$ associated degree , $6 \%$ bachelors degree).Their experience ranged between 1-36 with means ,( $\left.6.76 \&+\_7.03\right)$ years, \& 85.3-\% of them had staff nurse, \& majority of them are female $(73.3 \%)$.

\section{Data Collection Tool}

A questionnaire sheet was used to collect data for this study. It consists of two parts :The first part aimed at collect demographic data of the nurses including age, Sex, work position, years of experience, level of education.

The second part is a hospital survey to seek information about reporting of medication error. The survey was adopted from ( Allina Hospitals and Clinics, 2002 (C, Minneapolis, Minnesota).this tool , includes 13 questions, divided into two parts :

First part : Information about Reporting of medication error in hospital (6 questions).

Second part: Information about Reporting of medication error in department(7 question ).

The response to each question was on a 5point Likert scale that ranges from 1 and 2 (agree and strongly agree) to 3- 5 (disagree, strongly disagree and not applicable). For each section, the scores of the items were summed-up and the total divided by the number of the items, giving a mean score for the part. These scores were converted into a percent score. Nurse's opinion was considered "agree" if the percent score was $60 \%$ or more (corresponding to scores 1 and 2 on the scale for agree and strongly agree, respectively), and "disagree" if less than $60 \%$ (corresponding to disagree, strongly disagree and not applicable ). The scale content validity was done through experts' opinions, and its reliability was measured by Cronbach alpha coefficient which was 0.79 .

\section{procedure}

Permission to conduct the study was taken from the research committee in College of Applied Medical Sciences - Taif University after explanation of the aim of the study and the survey was conducted from November,2012 to December,2012. Informed consent to participate in the study was obtained from the staff nurse after clarification of the aim of the study. A staff meeting(Morning, afternoon \& night shift ) was done under the supervision of the head nurse to clarify the purpose, objectives and nature of the study as well as to explain the way of answering the questioner. Each nurse in the study subjects was interviewed individually to collect the necessary data and asked to fill out the questioner in 20 minutes. Upon the completion, the questioner was submitted to Statistical Analysis.

\section{Ethics and human rights}

An informed consent was obtained from all the participants before collecting any data. Explanation of the study aim in a simple and clear manner was done to each participant. No harmful maneuvers and no hazards were anticipated. All data were considered confidential. Participants were informed about their right to withdraw from the study at any time without giving any reason.

Statistical Analysis:

Data entry and statistical analysis were done using SPSS16.0 statistical software packages. Data were presented using descriptive statistics in the form of frequencies and percentages for qualitative variables. 


\section{Result :}

Table (1) Nurses opinion about reporting of medication errors in hospitals $\mathrm{N}=150$

\begin{tabular}{|c|c|c|c|c|c|c|}
\hline \multirow[t]{2}{*}{ Variables } & \multicolumn{2}{|c|}{$\begin{array}{c}\text { Agree \& } \\
\text { Strongly } \\
\text { Agree }\end{array}$} & \multicolumn{2}{|c|}{$\begin{array}{c}\text { Disagree \& } \\
\text { Strongly } \\
\text { Disagree }\end{array}$} & \multicolumn{2}{|c|}{$\begin{array}{c}\text { Not } \\
\text { Applicable }\end{array}$} \\
\hline & $\mathbf{N}$ & $\%$ & $\mathbf{N}$ & $\%$ & $\mathbf{N}$ & $\%$ \\
\hline $\begin{array}{l}\text { 1. Senior managers at my hospital communicate } \\
\text { to me that patient safety is a high priority }\end{array}$ & 144 & 96.0 & 6 & 4 & ----- & ----- \\
\hline $\begin{array}{l}\text { 2.The medication protocols in my hospital are } \\
\text { too complex }\end{array}$ & 61 & 40.0 & 89 & 59.4 & ----- & ----- \\
\hline $\begin{array}{l}\text { 3. The process of reporting errors at my hospital is } \\
\text { cumbersome }\end{array}$ & 68 & 45.3 & 81 & 54 & 1 & .7 \\
\hline $\begin{array}{l}\text { 4-I believe that a medical error is the result of a } \\
\text { failure of a complex system }\end{array}$ & 81 & 54 & 69 & 46.0 & ---- & ---- \\
\hline $\begin{array}{l}\text { 5-New technologies, such as electronic medical } \\
\text { records or Pyxis, are creating a safer environment } \\
\text { for patients in my hospital. }\end{array}$ & 102 & 68.0 & 26 & 17.3 & 22 & 14.7 \\
\hline $\begin{array}{l}\text { 6-New technologies available in my hospital are } \\
\text { fully utilized to help prevent medical errors }\end{array}$ & 102 & 68.0 & 40 & 26.6 & 8 & 5.3 \\
\hline
\end{tabular}

\section{Fig.1 : Nursing opinion about reporting of medication errors in hospitals $(\mathrm{N}=150)$}

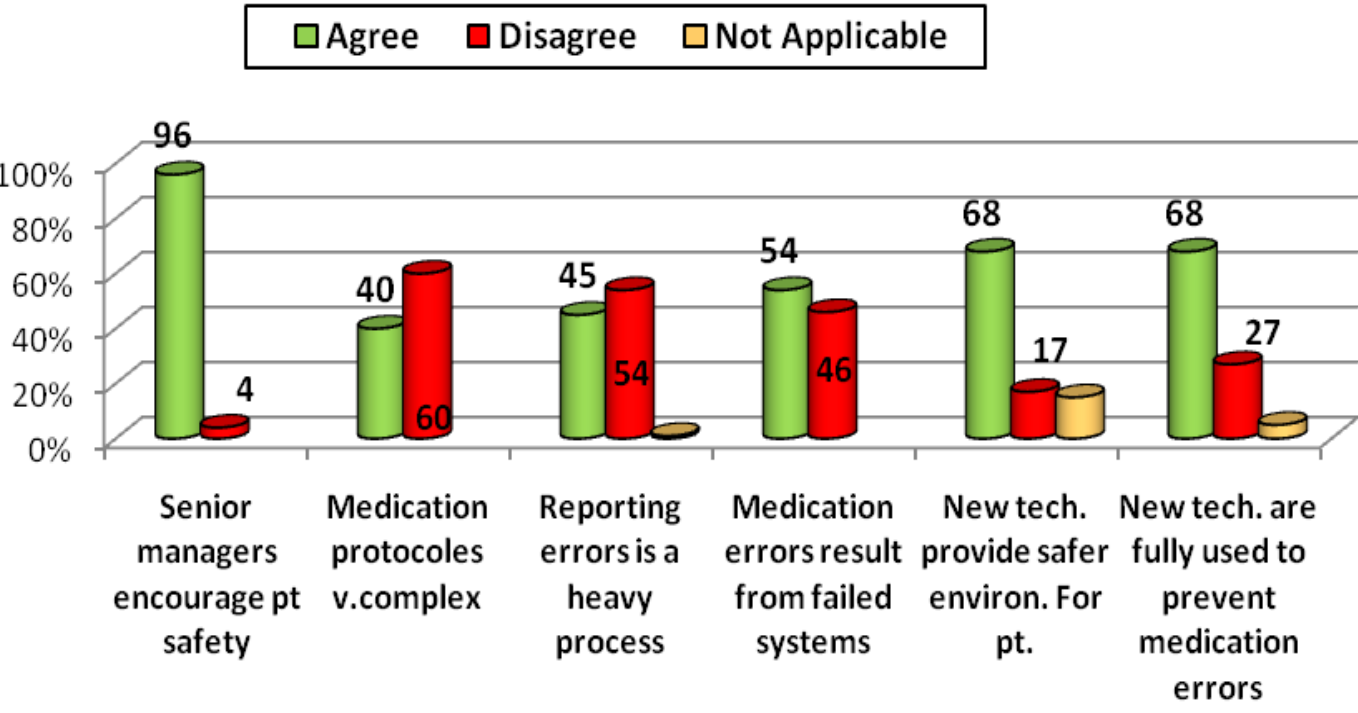


Table (2) Nurses opinion about reporting of medication errors In departments $\mathbf{N}=150$

\begin{tabular}{|c|c|c|c|c|c|c|}
\hline \multirow[t]{2}{*}{ Variables } & \multicolumn{2}{|c|}{$\begin{array}{r}\text { Agree \& } \\
\text { Strongly } \\
\text { agree } \\
\end{array}$} & \multicolumn{2}{|c|}{$\begin{array}{r}\text { Disagree\& } \\
\text { Strongly } \\
\text { disagree }\end{array}$} & \multicolumn{2}{|c|}{$\begin{array}{c}\text { Not } \\
\text { applicable }\end{array}$} \\
\hline & $\mathbf{N}$ & $\%$ & $\mathbf{N}$ & $\%$ & $\mathbf{N}$ & \begin{tabular}{|l|}
$\%$ \\
\end{tabular} \\
\hline $\begin{array}{l}\text { 1. My department/unit acts on reported information } \\
\text { related to medical errors (near miss, incident, sentinel } \\
\text { event) to improve patient safety. }\end{array}$ & 142 & 94.7 & $\overline{8}$ & 5.3 & & \\
\hline $\begin{array}{l}\text { 2. Individuals are supported for reporting medical } \\
\text { errors. }\end{array}$ & 128 & 85.4 & 22 & 14.6 & & \\
\hline $\begin{array}{l}\text { 3.My department/unit places blame on individuals when } \\
\text { an error is reported }\end{array}$ & 72 & 48.0 & 78 & 52.0 & & \\
\hline $\begin{array}{l}\text { 4.I fear there will be negative consequences associated } \\
\text { with reporting medical errors. }\end{array}$ & 86 & 57.4 & 63 & 42.5 & 1 & \begin{tabular}{|l}
.7 \\
\end{tabular} \\
\hline $\begin{array}{l}\text { 5.My workload interferes with my ability to practice } \\
\text { patient safety }\end{array}$ & 93 & $62 \%$ & 57 & $48 \%$ & & \\
\hline $\begin{array}{l}\text { 6.I feel comfortable reporting medical errors made by } \\
\text { co-workers. }\end{array}$ & 71 & $47.4 \%$ & 77 & 51.4 & 2 & \begin{tabular}{|l|l}
1.3 \\
\end{tabular} \\
\hline $\begin{array}{l}\text { 7-I work in an environment where I can openly } \\
\text { communicate my opinions about patient care practices. }\end{array}$ & 99 & $66 \%$ & 50 & 33.8 & 1 & $\mid .7$ \\
\hline
\end{tabular}

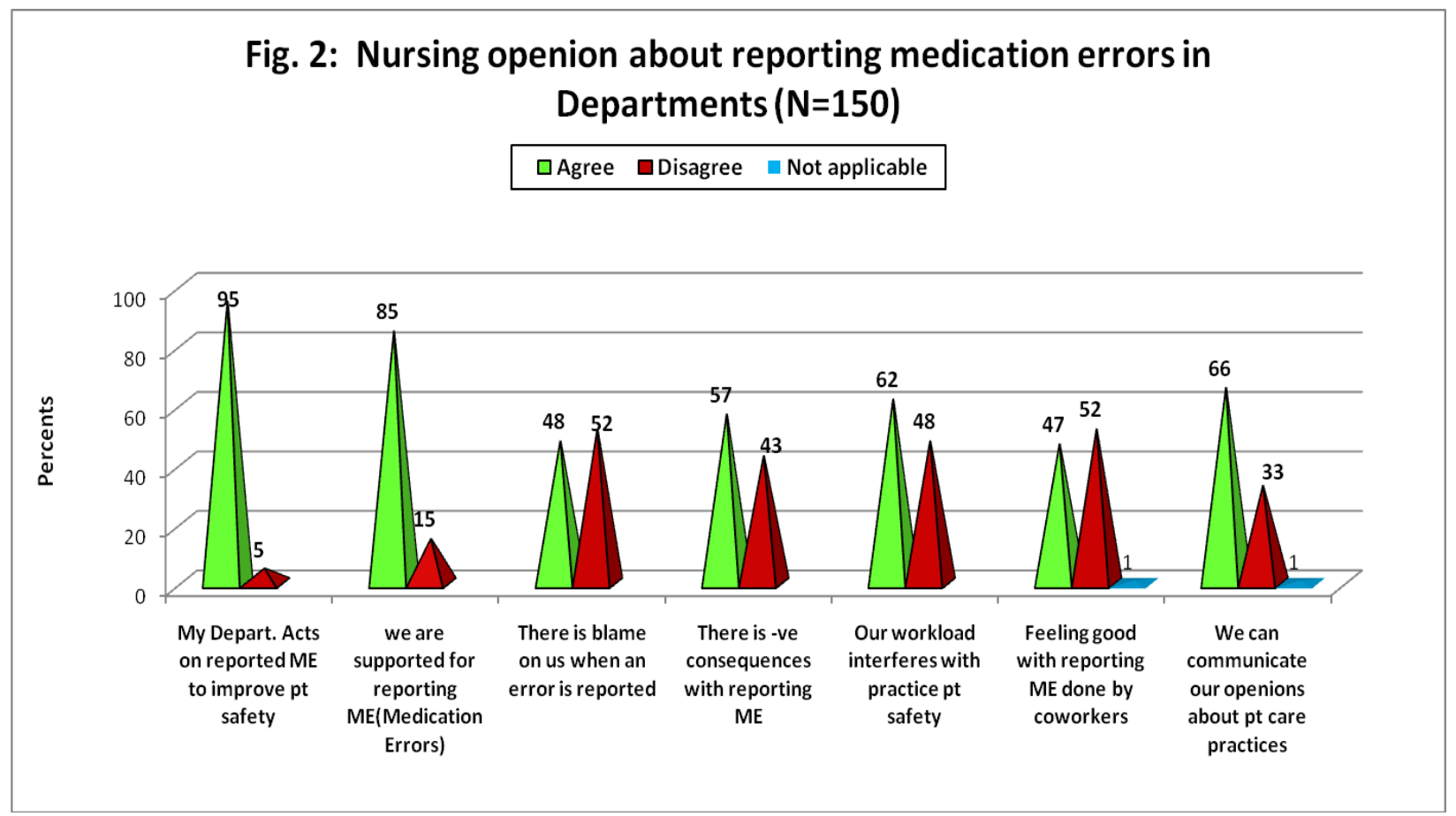




\section{Results :}

Table (1) \& figure (1), illustrate , Nurses opinion about reporting of medication errors In hospital, it was found that ,The majority of nurse reported ( agree \& strongly agree), about four out of six items related to, Senior managers at my hospital communicate to me that patient safety is a high priority, New technologies, such as electronic medical records or Pyxis, are creating a safer environment for patients in their hospital and New technologies available in their hospital are fully utilized to help prevent medical errors \& believe that a medical error is the result of a failure of a complex system,( $96 \%, 68.0 \%$ and $54 \%$,respectively), \& most nurses disagree $\&$ strongly disagree regard medication protocols in hospital are too complex, the process of reporting errors at their hospital is cumbersome, (59.4\%\&54\%, respectively).

Table (2)\&figur( 2), illustrate , Nurses opinion about reporting of medication errors in department ,it was found that ,The majority of nurse reported ( agree \& strongly agree), about five out of seven items related to, ,department/unit acts on reported information related to medical errors (near miss, incident, sentinel event) to improve patient safety, Individuals are supported for reporting medical errors, work in an environment where I can openly communicate my opinions about patient care practices, workload interferes with my ability to practice patient safety \& I fear there will be negative consequences associated with reporting medical errors $(94.7 \%, 85.4 \%, 66 \%, 62 \% \& 57.4 \%$,respectively). $\&$ two out of seven items related to , ( disagree \& strongly disagree ), regard department/unit places blame on individuals when an error is reported \& feel comfortable reporting medical errors made by co-workers, ( 52\% \&51.4,respectively ).

\section{Discussion:}

The medication process is a complex and includes a number of phases: Prescribing, transcribing, dispensing, administering, and monitoring. Errors can occur at all points of this process. The highest rates of error occur in the ordering phase, followed by the administration phase.

\section{(Harding \& Petrick, 2007).}

The present study aimed to : Identify nurse perceptions about reporting of medication error in Taif- Hospital. Table (1),shows that , The majority of nurses reported ( agree \& strongly agree), about four out of six items related to senior managers at their hospitals communicate to them that patient safety is a high priority-(96\%), this study supported by (Expert group on safe medication practice ,2006
\&Sara , 2005 ),who reported that the manager can be a positive tone for error prevention .

As regard new technology, $(68.0 \%)$ agree and strongly agree, new technologies, such as electronic medical records or Pyxis, are creating a safer environment for patients in their hospital ,available and fully utilized to help prevent medical errors. This result is supported by(The Health Foundation,2011\& Dennison, 2007), who reported that several types of information technologies can be used to decrease rates of medication errors, computerized physician order entry with decision support significantly reduces serious inpatient medication error rates in adults.

As regard to complexity of medication protocol, nurses disagree $\&$ strongly disagree, that the medication protocols are too complex and the process of reporting errors at their hospital is cumbersome ,(59.5\% and 54\%,respectively ), as shown in table (1), this result in accordance with, (Chaudhury, etal.., 2009), who reported that, medical errors result from the interplay of multiple factors that include, among others: complexity of tasks involved, work culture, and physical environment.

Table (2), investigate nursing opinion about reporting of medication error in the department, it was found that ,the majority of nurses reported

( agree \& strongly agree), about five out of seven items : department/unit acts on reported information related to medical errors to improve patient safety, Individuals are supported for reporting medical errors, working in an environment where they can openly communicate their opinions about patient care practices, workload interferes with their ability to practice patient safety \& their fear will have negative consequences associated with reporting medical

errors, $(94.7 \%, 85.4 \%, 66 \%, 62 \%$, and $57.4 \%$,respectivel $\mathrm{y})$. This result is supported by (Chaudhury, etal..., 2009), who reported that management decisions and organization processes, such as staff hierarchy, pattern and quality of staff communication, staff workload, and work culture, can effect nursing and medication errors either directly (example, miscommunication of medication information) or indirectly by creating error-producing conditions (example, staff fatigue leading to error).

As regard to unit blame , ( disagree \& strongly disagree ), nurses report that department/unit places blame on individuals when an error is report and they feel comfortable reporting medical errors made by co-workers, $(52 \%$, and $51.4 \%$,respectively)), shown in table( 2).Gain work group(2005), showed that in a no -blame culture ,there was general agreement that even the most experienced knowledgeable and caring 
workers could make mistakes that could lead to patient harm.

\section{Conclusion:}

Reporting errors in a clear and transparent with no blame in workplace, decreasing workloads, applying quality standards, informatics technology and selecting qualified health personnel are the suitable solution for reducing medication errors.

\section{Recommendations:}

Preparing an educational training course for documenting and reporting system through utilization of information technology and quality standards in medication administration according to hospital police .

\section{References:}

1. Allina Hospitals and Clinics, Minneapolis, Minnesota, 2002.

2. Ansari, M., Neupane, D.,(2009), Study on determination of errors in prescription writing: A semi electronic perspective, Kathmand University Medical Journal (2009), Vol. 7, No. 3, Issue 27, 238-241.

3. Arun, K. D., Subish, P., Pathiyil, R. S., Pranaya ,M., Mukhyaprana, P., Ram B.B.\& Anupa ,K. C.,(2006). Introduction to medication errors and the error prevention initiatives in a teaching hospital in Western Nepal. Pak. J. Pharm. Sci., 2006, Vol.19(3), 244-251.

4. Chaudhury, Habib, Mahmood, Atiya, \& Valente, Maria, (2009). The Effect of Environment Design on Reducing Nursing Errors and Increasing Efficiency in Acute Care Settings. Environment and Behavior. (2009, May). (pp. 756-757). Retrieved from Sage Journals Online via http://eab.sagepub.com/content/41/6/755.short

5. Cochen,M.(2000). Why error reporting systems should be voluntary. British Medical Journal.320.728-729.

6. Dennison, R., D., (2007). A Medication Safety Education Program to Reduce the Risk of Harm Caused by Medication Errors. The Journal of Continuing Education in Nursing. July/August. (pp. 178). Retrieved from http://www.jcenonline.com/view.asp?rid=22880

7. Expert Group on Safe Medication Practices ,(2006). Creation of a better medication safety culture in Europe: Building up safe medication practices.

8. Gain working group E, medication safety Alert,septimber,(2006).

9. Harding, L., \& Pet rick, T., (2008). Journal of Nursing Education. , January, Vol. 47. No. 1.
Retrieved from http://www.journalofnursingeducation.com/show abst.asp?thing $=34010$

10. Health Foundation ,2011,www.health.org.uk ,Follow us on Twitter: www.twitter.com/HealthFdn

11. Hecht,M,Jackson,R.,\&Pitts,M.(2005).Culture: Intersection of inter group identity theories.InJ.Harwood\&H.Giles(Eds).Intergroup communications: multiple perspectives(pp.2142).New York:Peter lang.

12. Hughes, $\mathbf{T}$ and Farrow, T. (2006). Preparing cultural safety assessment. Kai Tiaki Nursing New Zealand, February, pp 12-14

13. Irshaid, Y.,M., Al Homrany M., Hamdi, A.,(2005).Compliance with good practice in prescription writing at outpatient clinics in Saudi Arabia.

14. Kaushal, r. and Bates w.,(2002) .Information technology and medication safety: what is the benefit?, Qual Saf Health Care 2002; 11:261-265

15. Kohn,l.,Corrigan,j.,\& Donaldson.(2000).To err is human: Building a safer health system.washington,D.C:National Academy press

16. Larson,l.,(2000).Ending the culture of blame.Trustee,53(2),6-10

17. Mary, A. F., Mary, B. F., Ronda, G. H., (2005 ). The Nurse's Role in Promoting a Culture of Patient Safety.

18. Penny و L., Tim ,D., David ,T., Mary, P., Val ,W. FRCP.\& Darren M. ,(2008), The prevalence and incidence of prescribing errors: Systematic Review. tim.dornan@manchester.ac.uk

19. Qureshi ,N.A. , Neyaz ,Y., Khoja ,T.,(2011) • Effectiveness of three interventions on primary care physicians' medication prescribing in Riyadh city, Saudi Arabia. Eastern Mediterranean Health Journal, 2011, 17(2):172179

20. Sara ,B.,(2005). Medical Errors: Five Years After the IOM Report, The Commonwealth Fund/John F. Kennedy School of Government Bipartisan Congressional Health Policy Conference, January 13-15, 2005 